\title{
Enhanced Solar Photoelectrochemical Conversion Efficiency of ZnO:Cu Electrodes for Water-Splitting Application
}

\author{
Rekha Dom, ${ }^{1}$ Lijin Rose Baby, ${ }^{1}$ Hyun Gyu Kim, ${ }^{2}$ and Pramod H. Borse ${ }^{1}$ \\ ${ }^{1}$ Solar $\mathrm{H}_{2}$ PEC Lab., International Advanced Research Centre for Powder Metallurgy and New Materials, \\ Balapur PO, Hyderabad, Andhra Pradesh 500 005, India \\ ${ }^{2}$ Division of High Technology Materials Research, Korea Basic Science Institute (KBSI), Busan 618-230, Republic of Korea \\ Correspondence should be addressed to Pramod H. Borse; phborse@arci.res.in
}

Received 30 May 2013; Revised 7 August 2013; Accepted 9 August 2013

Academic Editor: Lizhi Zhang

Copyright (C) 2013 Rekha Dom et al. This is an open access article distributed under the Creative Commons Attribution License, which permits unrestricted use, distribution, and reproduction in any medium, provided the original work is properly cited.

\begin{abstract}
n-type $\mathrm{ZnO}: \mathrm{Cu}$ photoanodes were fabricated by simple spray pyrolysis deposition technique. Influence of low concentration (range $\sim 10^{-4}-10^{-1} \%$ ) of $\mathrm{Cu}$ doping in hexagonal $\mathrm{ZnO}$ lattice on its photoelectrochemical performance has been investigated. The doped photoanodes displayed 7-time enhanced conversion efficiencies with respect to their undoped counterpart, as estimated from the photocurrents generated under simulated solar radiation. This is the highest enhancement in the solar conversion efficiency reported so far for the $\mathrm{Cu}$-doped $\mathrm{ZnO}$. This performance is attributed to the red shift in the band gap of the $\mathrm{Cu}$-doped films and is in accordance with the incident-photon-current-conversion efficiency (IPCE) measurements. Electrochemical studies reveal an n-type nature of these photoanodes. Thus, the study indicates a high potential of doped ZnO films for solar energy applications, in purview of the development of simple nanostructuring methodologies.
\end{abstract}

\section{Introduction}

Ever growing environmental imbalances as "green house effect" and an ever increasing energy demands of man have accelerated the search of the photoactive materials for water splitting under solar light irradiation [1-5]. At present, the development of an efficient and a stable photoanode is one of the key issues in the solar photon-induced photoelectrochemical (PEC) water-splitting research. Transition metal oxides are the promising candidates for the PEC hydrogen production due to their high stability in an aqueous solution, their low cost, and their scalability for the large-scale applications [6-9]. Further, the important parameters as their appropriate band energetics, low electrical resistance, and the good corrosion resistance in an electrolyte make them the best suited candidate for the PEC photoanode applications $[2,10]$. However, most of the metal oxides studied in the past exhibit a large band gap, thus making them inefficient in absorbing the visible light photons, which form the major portion of sun light [11-13]. Thus, it becomes necessary to explore the new processing methods to reduce the photoanode material band gap, and they efficiently utilize the solar light reaching earth surface and generate the useful energy.

Zinc oxide $(\mathrm{ZnO})$ is one of the most important and a well-studied metal oxide that received considerable attention for various applications, such as pigment, photoluminescence device, sensors, piezoelectric element, and varistor [14, 15]. Nevertheless, it has also been extensively studied as a photoanode system due to its high electron mobility, and as it possesses a good resistance to photocorrosion [16]. This wide band gap semiconductor exhibits a direct band gap of 3.2$3.36 \mathrm{eV}$ at room temperature and an exciton binding energy of $60 \mathrm{meV}$ [17]. The band energetics required to photosplit water are quite similar to $\mathrm{TiO}_{2}[1]$, which is the first material reported for PEC splitting of water; however, the large band gap remains a key concern. Despite $\mathrm{ZnO}$ is a poor absorber of visible light photons $(\mathrm{Eg} \sim 3.2 \mathrm{eV})$, its higher electron mobility $[15,18-20]$ which is even larger than $\mathrm{TiO}_{2}\left(155 \mathrm{~cm}^{2} \mathrm{~V}^{-1} \mathrm{~s}^{-1}\right.$ versus $10^{-5} \mathrm{~cm}^{2} \mathrm{~V}^{-1} \mathrm{~s}^{-1}$ ) makes it superior and well-suited material for current generating device applications in PEC solar cells. 
Metal and nonmetal ion doping in $\mathrm{ZnO}$ lattice has received tremendous attention during the past few decades. This is because transition metal-ion doping is known to significantly red shift its host lattice optical absorption in visible light [21-23], as well as it yields a photoluminescent material. In one such report, $\mathrm{ZnO}$ was modified to achieve a material showing the capability of solar light-induced photoelectrochemical water splitting [18]. Recently, Sharma et al. [22, 23] studied the effect of incorporation of chromium, nickel, and ruthenium ions in $\mathrm{ZnO}$ lattice to understand its effect on the PEC behavior of the nanocrystalline films. Dong et al. [24] reported deposition of $\mathrm{ZnO}: \mathrm{Fe}$ array thin films using simple sol-gel hydrothermal technique, which exhibited 1.6 times enhancement in methylene blue photodegradation efficiency. Further, Zhang et al. [25] also reported an enhanced photocatalytic activity of Fe-doped $\mathrm{ZnO}$ nanowires synthesized using hydrothermal technique. Wu et al. [26] showed that chromium-doped $\mathrm{ZnO}$ nanowires show a better photocatalytic activity for decoloration of methyl-orange than P25 $\left(\mathrm{TiO}_{2}\right)$ as well as $\mathrm{ZnO}$ nanomaterial. The report on cobaltdoped $\mathrm{ZnO}$ nanorod photocatalysts by Lu et al. [27] demonstrated an increased photocatalytic activity for the decomposition of Alizarin red dye under the visible light as compared to the pure $\mathrm{ZnO}$ nanorods. Bahadur and Rao [28] reported on the doping of cobalt ion in $\mathrm{ZnO}$ lattice to enhance the photoelectrochemical properties. Further, the 2\% La-doped $\mathrm{ZnO}$ nanowires have shown an increased activity in the degradation of Rhodamine B (RhB) [29]. Recently, Ishihara et al. [30] reported the visible light emission due to luminescence from Cd-doped $\mathrm{ZnO}$ films and associated it with the bandgap narrowing. There are also reports on the improved photocatalytic performance using Ag-doped $\mathrm{ZnO}[31,32]$. However, with Ag being expensive, utilization of a low cost metal ion for doping $\mathrm{ZnO}$ is more desirable. With copper being an economic alternative to $\mathrm{Ag}$, it has been sought by several researchers. It is an abundant metal on the earth, which possesses a tremendous application potential as a catalyst. Atomically, copper shows analogous physical and chemical properties as to $\mathrm{Zn}$. $\mathrm{Cu}^{2+}$ can substitutionally occupy $\mathrm{Zn}^{2+}$ site of the hexagonal $\mathrm{ZnO}$ crystal lattice and thus induce a deep acceptor state. Such acceptor state and $\mathrm{O}$ vacancy states may improve the electrical transport properties as well as the photocatalytic properties. Thus, it is an important dopant with respect to PEC hydrogen production application.

Inspite of high potential of $\mathrm{Cu}$-doped $\mathrm{ZnO}$ photocatalysts, there are limited reports on $\mathrm{Cu}$-doped photocatalysts. Few significant reports focusing on the photocatalytic and photo-electrocatalytic application are described here. It is well known that heavy copper doping is known to yield $p$ type lattice. Öztas and Bedir reported a study on the spray deposited $\mathrm{ZnO}: \mathrm{Cu}$ films of different film thickness [33] for gas sensor application. As far as conductivity is concerned, Rahmani et al. [34] showed a Cu-doping concentrationdependent transition of $\mathrm{ZnO}$ films electrical conductivity from $n$-type to $p$-type conductivity for such films deposited by spray pyrolysis technique. Further, they reported the application of these films in $\mathrm{NO}_{2}$ gas sensing. Similarly Mari et al. [35] reported, p-type $\mathrm{Cu}$-doped $\mathrm{ZnO}$ films obtained by electrodeposition method. Thus, it can be clearly understood that a variation in $\mathrm{Cu}$-doping concentration renders either $n$ type or a p-type conductivity to host $\mathrm{ZnO}$ lattice. Such tuning of conductivity is highly useful for photocatalytic applications. Especially, there are few reports on the photocatalytic application of $\mathrm{Cu}$-doped $\mathrm{ZnO}$. Jongnavakit et al. reported the highest photodegradation rate of methylene blue by using $\mathrm{Cu}$-doped $\mathrm{ZnO}$ films deposited by sol-gel dip coating method [36]. Mohan et al. showed that the $\mathrm{Cu}$-doped $\mathrm{ZnO}$ nanorods showed an enhanced performance in degrading Resazurin dye [37]. Sharma et al. reported an enhancement in the PEC currents due to $\mathrm{Cu}$ doping [38] in the $\mathrm{ZnO}$ lattice. In another report, Hsu and Lin showed a 2-fold enhancement in the PEC efficiency for $n$-type $\mathrm{Cu}$-doped $\mathrm{ZnO}$ nanorods obtained by electrodeposition technique [39]. Scarcity of reports on solar photoelectrochemical water splitting by using $\mathrm{Cu}$-doped $\mathrm{ZnO}$ initiated our interest in producing $n$-type $\mathrm{Cu}$-doped $\mathrm{ZnO}$ electrode using economic spray pyrolysis deposition technique. In order to necessarily obtain an $n$-type conductivity [34], we restricted the initial $\mathrm{Cu}$-doping concentration to a very low concentration. To the best of our knowledge, in the past, there is no specific report on the doping of low $\mathrm{Cu}$ concentrations and its utilization for PEC electrode.

In the present work, $\mathrm{Cu}$ doping is carried out for different doping concentrations in the concentration range of $10^{-4}$ to $10^{-1}$ during a simple spray pyrolysis deposition of $\mathrm{ZnO}$ films. As-deposited films were characterized to study their structural, optical, and the morphological properties. Further, the effect of $\mathrm{Cu}$-doping concentration on the PEC performance is optimized. The study demonstrates the development of solar radiation absorbing $\mathrm{Cu}$-doped $\mathrm{ZnO}$ films by using a simple deposition technique.

\section{Experimental}

2.1. Film Deposition and Photoanode Fabrication. Simple spray pyrolysis technique was adopted to deposit the $\mathrm{Cu}$ doped $\mathrm{ZnO}$ films. An aqueous solution of $\mathrm{Zn}\left(\mathrm{NO}_{3}\right)_{2} \cdot 6 \mathrm{H}_{2} \mathrm{O}$ was used as precursor for zinc source. Zinc nitrate was dissolved in deionised water to prepare an aqueous solution of 0.25 molarity. To induce and to control the $\mathrm{Cu}$ doping concentration, equimolar aqueous solution of $\mathrm{Cu}\left(\mathrm{NO}_{3}\right)_{2} \cdot 3 \mathrm{H}_{2} \mathrm{O}$ was mixed with the Zinc nitrate solution by volume ratio. Fluorine-doped tin oxide (FTO- $12 \Omega$-cm Pelkington) glass substrates were used during the deposition of the $\mathrm{ZnO}$ films. On the priori the substrates were thoroughly cleaned and dried in an oven. The deposition temperature was kept at $450^{\circ} \mathrm{C}$. Films of different thickness were deposited by variation in the number of spraying cycles. Undoped $\mathrm{ZnO}$ films were also deposited to be a standard reference in the study. In order to measure the photoactivity, electrode fabrication was carefully carried out by using the deposited films. An electrode of unit area $1 \mathrm{~cm}^{2}$ was used that was connected via $\mathrm{Cu}$ wire to apply the external bias. High purity Ag paste was used for making the contacts. Neatly sealed electrode was used for PEC measurements.

2.2. Characterization. Structural studies were carried out using X-ray diffraction studies. Advanced XRD equipment (Bruker AXS D8), equipped with a Lynx eye detector, and 
$\mathrm{X}$-ray gun generating monochromatic $\mathrm{CuK}_{\alpha}$ radiation $(\lambda=$ $1.54 \AA$ ) at $40 \mathrm{kV}$ and $40 \mathrm{~mA}$ were used for X-ray diffraction (XRD) studies. The scans were recorded in the $2 \theta$ range of $20-$ $90^{\circ}$ with a step size of $0.001^{\circ}$ at $2 \mathrm{sec} / \mathrm{step}$. The film morphological studies were carried out by scanning electron microscopy using FESEM (Hitachi model S4300SE/N) with the instrument operated at $20 \mathrm{kV}$ and equipped with energydispersive X-ray analyzer (EDAX USA, PV7747/36ME). Additionally, studies were carried out to investigate the optical properties using a UV-Visible spectrophotometer (PerkinElmer 6500 model).

2.3. Photoelectrochemical Study. Photoelectrochemical measurements were carried out in a specially designed and fabricated PEC cell consisting of a quartz window. The photocurrents were recorded under simulated solar light (AM1.5G Newport-91160-1000 model). The photoelectrodes of area 1 $\times 1 \mathrm{~cm}^{2}$ fabricated using the deposited films were used as working electrodes, and the graphite (or $\mathrm{Pt}$ ) was used as counter. Saturated calomel electrode (SCE) was used as reference electrode in all measurements. An aqueous solution of $0.5 \mathrm{M} \mathrm{NaOH}$ was used as electrolyte during the experiments. The electrochemical workstation (Potentiostat Galvanostat PARSTAT 2273 model EG\&G Princeton Applied Research fitted with an impedance analyzer) was used to record the photocurrent variation with applied potential under different light sources. For the estimation of the wavelengthdependent efficiency, that is, incident photon-to-current conversion efficiency (IPCE), a monochromator (Oriel model 74125) fitted with a $300 \mathrm{~W}$ Xenon lamp was used. The spectra were recorded in the wavelength range of 250 to $700 \mathrm{~nm}$ with an interval of $10 \mathrm{~nm}$.

\section{Results and Discussions}

3.1. Structural Properties. The structural properties of the as-deposited films of $\mathrm{ZnO}$ with different concentrations of $\mathrm{Cu}$ doping were investigated from $\mathrm{X}$-ray diffraction studies. Figure 1 displays the XRD patterns of pure and the doped $\mathrm{ZnO}$ films. All the films exhibit crystalline wurtzite structure of $\mathrm{ZnO}$ (JCPDS 036-1451), demonstrating that there is no distortion of $\mathrm{ZnO}$ host lattice due to such low level of $\mathrm{Cu}$ doping. The major reflection from (002) plane was observed in all the films; however, there was an increase in (002) peak intensity with an increase in the $\mathrm{Cu}$ concentration. Peaks corresponding to FTO substrate are also detected in all the spectra. No characteristic reflections of the $\mathrm{Cu}_{2} \mathrm{O}, \mathrm{CuO}$, or other impurity phases were detected. Expectedly, as there is negligible difference in the ionic radii of $\mathrm{Cu}$ and $\mathrm{Zn}$, the doping shows no effect related to $\mathrm{ZnO}$ host lattice distortion. Similar results have been reported in the literature for $\mathrm{Cu}$-doped $\mathrm{ZnO}$ films [33-35]. The crystallite size of all the films was estimated by using the Debye-Scherrer analysis [40]. It was found to lie in the range $14-18 \mathrm{~nm}$. This study thus indicates that the doping has no effect on the crystallite size in present doping concentration range. In order to have a deep insight of the possible effect on lattice microstrain, a detailed analysis was carried out. Figure 2 shows the magnified view of (002) peak for all the films; those are discussed in Figure 1. A negligible

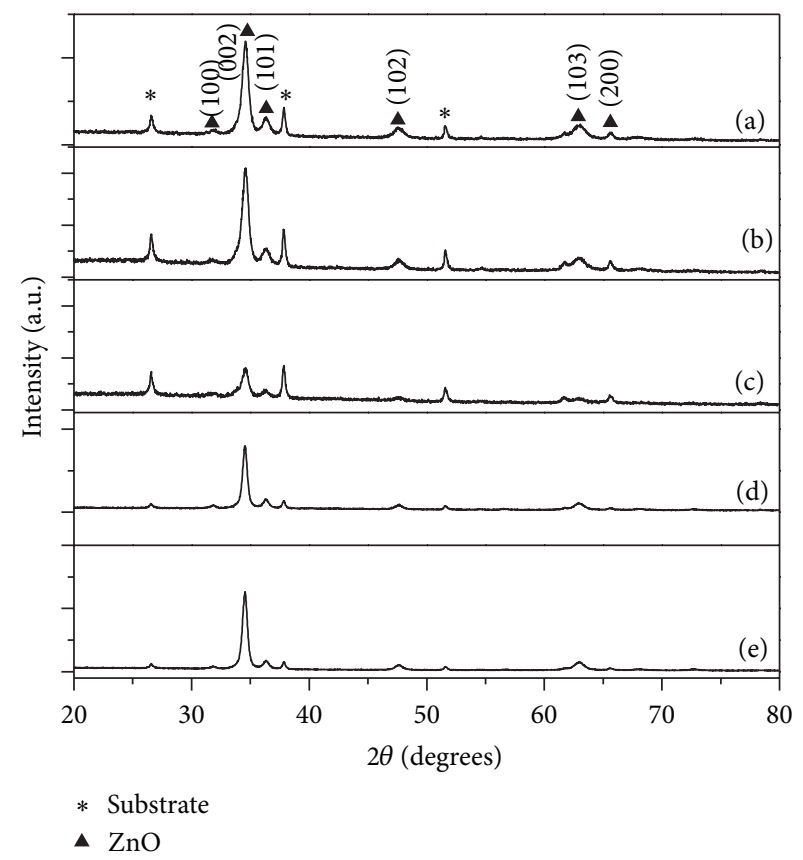

Figure 1: X-ray diffraction spectra of doped $\mathrm{ZnO}$ films with different concentrations of doping. (a) $\mathrm{ZnO}$, (b) $0.1 \mu \mathrm{M} \mathrm{Cu}^{2+}$, (c) $0.3 \mu \mathrm{M} \mathrm{Cu}^{2+}$, (d) $1.3 \mu \mathrm{M} \mathrm{Cu}^{2+}$, and (e) $26.4 \mu \mathrm{M} \mathrm{Cu}^{2+}$ concentrations.

shift in " $2 \theta^{\prime \prime}$ (nearly $0.04^{\circ}$ ) with respect to undoped film was observed for all the films. Nonetheless, though such negligible variation in " $2 \theta$ " was insufficient to induce lattice distortion, however, doping-induced microstrain was investigated to rule out if any damaging effect occurs at such low doping concentrations. It may be worth recalling that the dopinginduced lattice defects and their interaction with the hostlattice consequently result in the introduction of an inhomogeneous strain field, which exists even without application of any external force [41]. Such inhomogeneous strain fields, produced by various defects, strongly influence the X-ray diffraction profiles.

The microstrain $(\varepsilon)$ can be estimated from the following formula [23]:

$$
\varepsilon=\frac{\beta \cos \theta}{4}
$$

where $\beta$ is the full width at half maxima for diffraction peak exhibiting the diffraction angle of $2 \theta$. Table 1 displays the result of microstrain calculation for all the films. It clearly shows that though the magnitude of microstrain is very small, the samples with comparatively high $\mathrm{Cu}(1.3$ and 26.4) in concentration show a reduction in microstrain, thus demonstrating the copper doping. Further, reduction of the microstrain can be attributed to the possible decrease in lattice defects density at the grain boundary. It is also believed that variation ion in the crystallite size may not contribute to affect the microstrain. The structural study thus demonstrates the formation of hexagonal phase where the high $\mathrm{Cu}$-doping concentration (1.3 and $26.4 \mu \mathrm{M})$ can ably affect the dopinginduced microstrain in the $\mathrm{ZnO}$ host lattice. 


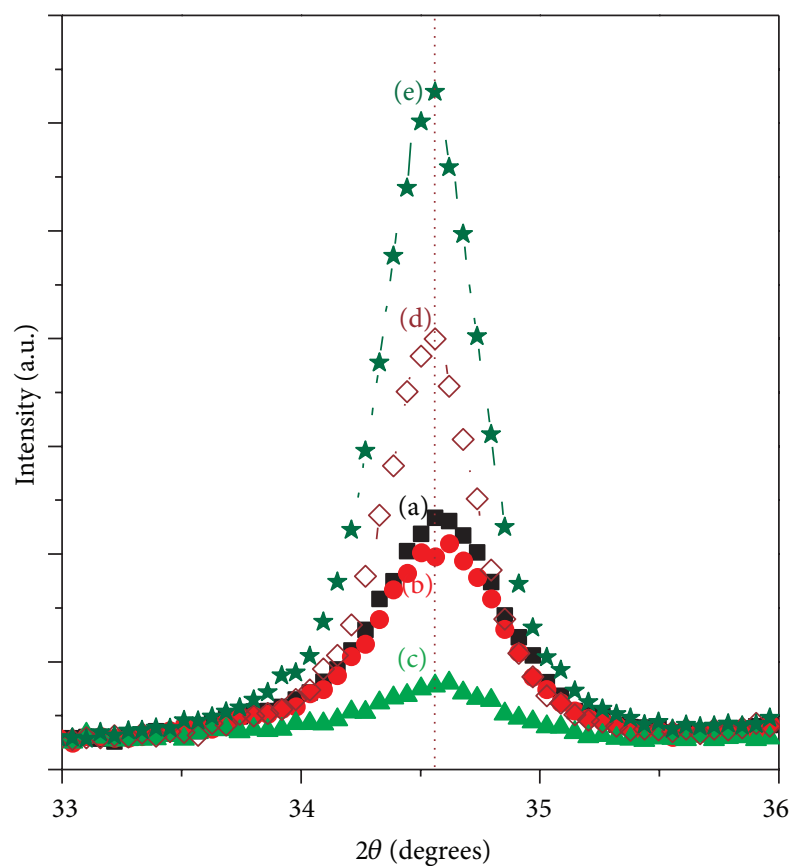
(a) Undoped
(b) $0.1 \mu \mathrm{M} \mathrm{Cu}^{2+}$
(c) $0.3 \mu \mathrm{M} \mathrm{Cu}^{2+}$
(d) $1.3 \mu \mathrm{M} \mathrm{Cu}^{2+}$
(e) $26.4 \mu \mathrm{M} \mathrm{Cu}^{2+}$

Figure 2: Peak intensity of (002) plane in doped $\mathrm{ZnO}$ films with different concentrations of $\mathrm{Cu}$ doping. (a) $\mathrm{ZnO}$, (b) $0.1 \mu \mathrm{M} \mathrm{Cu}^{2+}$, (c) $0.3 \mu \mathrm{M} \mathrm{Cu}^{2+}$, (d) $1.3 \mu \mathrm{M} \mathrm{Cu}^{2+}$, and (e) $26.4 \mu \mathrm{M} \mathrm{Cu}^{2+}$ concentrations.

TABle 1: Crystallite size and microstrain estimated from XRD studies for all $\mathrm{ZnO}$ films.

\begin{tabular}{lcc}
\hline $\begin{array}{l}\left(\mathrm{Cu}^{2+}\right) \text { initial } \\
\text { content }(\mu \mathrm{M})\end{array}$ & Crystallite size $(\mathrm{nm})$ & Microstrain $\varepsilon\left(10^{-3}\right)$ \\
\hline 0 & 14 & 0.15 \\
0.1 & 14 & 0.15 \\
0.3 & 14 & 0.15 \\
1.3 & 18 & 0.11 \\
26.4 & 17 & 0.12 \\
\hline
\end{tabular}

3.2. Optical Properties. Figure 3 shows the result of the optical characterization of the doped and undoped $\mathrm{ZnO}$ films. Figure 3(a) displays the absorption spectra of the undoped and doped films, thus demonstrating the doping-induced red shift in the band-gap of $\mathrm{ZnO}$ host lattice. It clearly shows that there is a shift in the absorption onset of $\mathrm{ZnO}$ lattice with an increase in the doping concentration from 0.1 to $26.4 \mu \mathrm{M}$. Further, an in-depth optical analysis was carried out and the band-gap was estimated using Tauc analysis [42]. Figure 3(b) shows Tauc analysis for all the films, which clearly indicates a major red-shifted band-gap of host lattice for the film doped with high $\mathrm{Cu}$ concentration. This clearly reveals that the $\mathrm{ZnO}$ lattice is doped by $\mathrm{Cu}$-ions, which is in similar agreement with the conclusion made from the structural investigations. The result of band-gap estimation is tabulated in Table 2 for the later discussions. This band-gap narrowing extends
TABLE 2: Photocurrent density, band gap, and flat band potential of undoped and $\mathrm{ZnO}$ films.

\begin{tabular}{lccc}
\hline $\begin{array}{l}\left(\mathrm{Cu}^{2+}\right) \text { initial } \\
\begin{array}{l}\text { content } \\
(\mu \mathrm{M})\end{array}\end{array}$ & $\begin{array}{c}\text { Photocurrent } \\
\text { density }\left(\mu \mathrm{A} / \mathrm{cm}^{2}\right)\end{array}$ & $\begin{array}{c}\text { Band gap } \\
(\mathrm{eV})\end{array}$ & $\begin{array}{c}\text { Flat band potential } \\
(\text { Volts versus SCE) }\end{array}$ \\
\hline 0 & 48 & 3.25 & -0.367 \\
0.1 & 203 & 3.23 & -0.415 \\
0.3 & 350 & 3.23 & -0.388 \\
1.3 & 350 & 3.17 & -0.358 \\
26.4 & 15 & 3.08 & -0.426 \\
\hline
\end{tabular}

the optical response of UV-active semiconductor, that is, doped $\mathrm{ZnO}$ to the visible region of electromagnetic spectrum.

It is important to mention that the efforts made to estimate the quantitative analysis of dopant $(\mathrm{Cu})$ failed, as the $\mathrm{X}$-ray photoelectron spectroscopy carried out was unable to detect very low concentration of $\mathrm{Cu}$ in the doped $\mathrm{ZnO}$ films. Reduction in the band gap thus facilitates excitation of an electron from the valence band to the conduction band, even under illumination of visible light photons. This is beneficial for achieving an improved PEC performance from a UVactive material [34-38]. This study confirms that the incorporation of an optimal concentration of $\mathrm{Cu}$ in $\mathrm{ZnO}$ can yield an efficient solar light absorbing optical system, which can be useful for the solar energy applications.

3.3. Morphological Study. Figure 4 shows the surface morphology of the $\mathrm{ZnO}$ films doped with different $\mathrm{Cu}$-doping concentrations. All the films exhibited a similar morphology, but with a variation in the features of grain. This is an indicative that with an increase in the $\mathrm{Cu}$-doping concentration from $0.1 \mu \mathrm{M}$ to $1.3 \mu \mathrm{M}$, the finer grains are obtained; however, the crystallite size estimated from XRD studies was found to remain unaltered. Interestingly, Jongnavakit et al. [36] reported that $\mathrm{Cu}$ doping of $\mathrm{ZnO}$ lattice reduces the grain size after doping. We can assume that such fine grains would render a favorable effect to the PEC performance in view of possible enhancement in the catalytic site over the film surface.

3.4. Photoelectrochemical Studies. Figure 5(a) shows the photocurrents generated from undoped and $\mathrm{Cu}$-doped $\mathrm{ZnO}$ films under simulated solar light. The dark current is shown as reference for the comparison. It clearly shows that even at a low level of $\mathrm{Cu}$ doping, the film shows a considerable enhancement in the photocurrent. Surprisingly, a 5-time enhanced photocurrent was generated by the doped film in comparison to the undoped counterpart at an applied bias of $1 \mathrm{~V}$ versus SCE. This is one of highest enhancement as compared to that reported by Hsu and Lin [39] for Cu-doped $\mathrm{ZnO}$ nanorods. Such nanorods showed an enhancement of 1.5 times. Further, our study clearly demonstrates a maximum enhancement of around 7 times at $0.6 \mathrm{~V}$ of applied bias, at desirably lower biasing voltage. This is the one of the maximum enhancement reported so far under the present applied bias. 


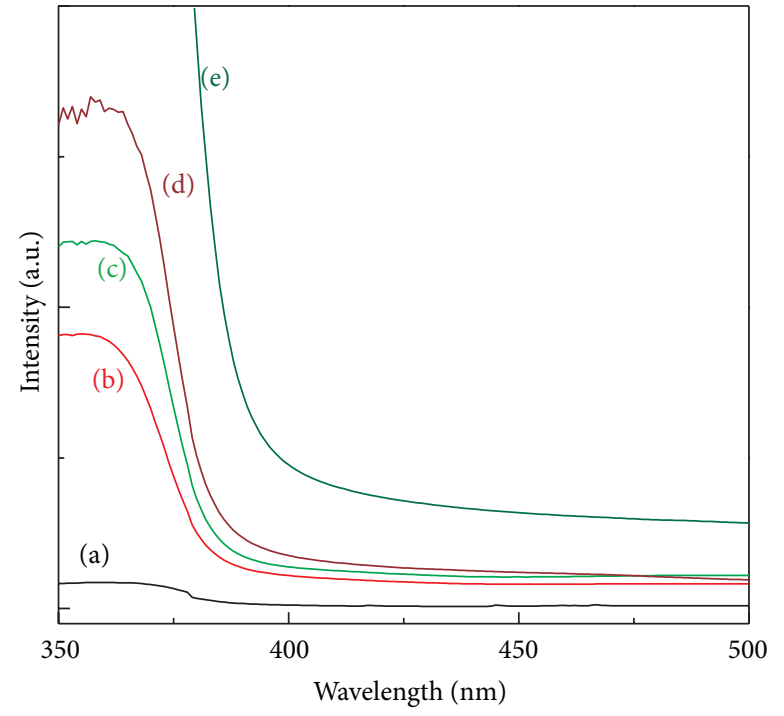
(a) Undoped
(d) $1.3 \mu \mathrm{M} \mathrm{Cu}^{2+}$
(b) $0.1 \mu \mathrm{M} \mathrm{Cu}^{2+}$
(c) $0.3 \mu \mathrm{M} \mathrm{Cu}^{2+}$
(e) $26.4 \mu \mathrm{M} \mathrm{Cu}^{2+}$

(a)

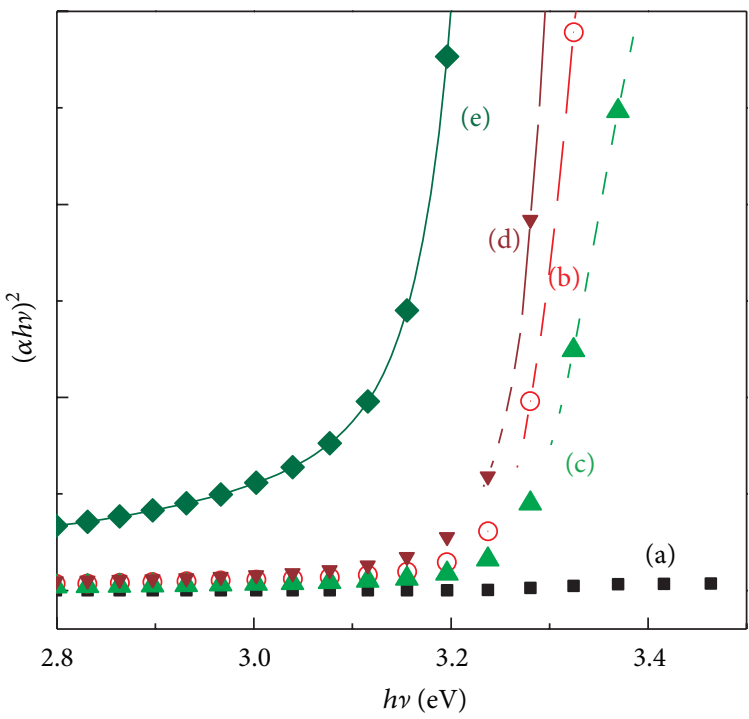
(a) Undoped
(d) $1.3 \mu \mathrm{M} \mathrm{Cu}^{2+}$
(b) $0.1 \mu \mathrm{M} \mathrm{Cu}^{2+}$
(e) $26.4 \mu \mathrm{M} \mathrm{Cu}^{2+}$

(c) $0.3 \mu \mathrm{M} \mathrm{Cu}^{2+}$

(b)

Figure 3: (a) Absorption spectra of doped ZnO films with different concentrations of doping. (b) Tauc plots of the same films.

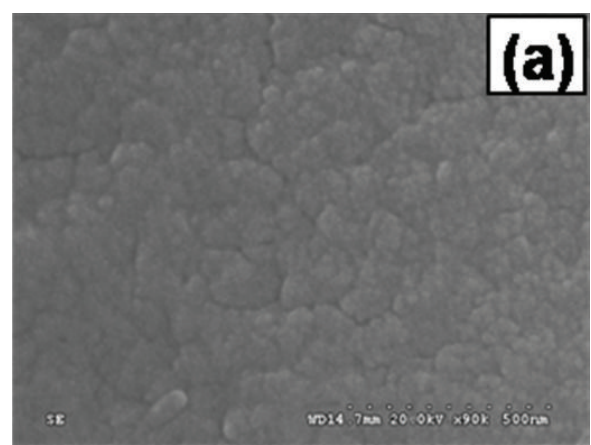

(a)

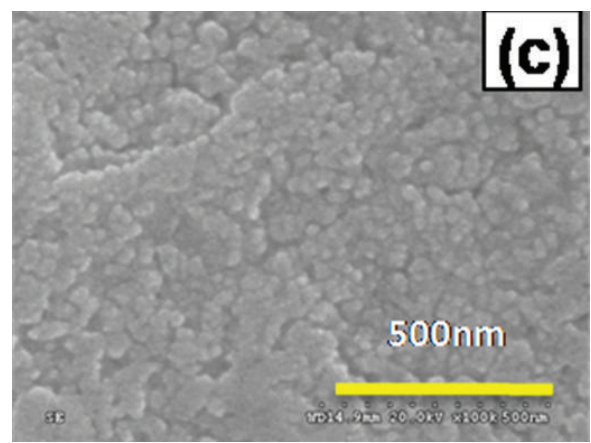

(c)

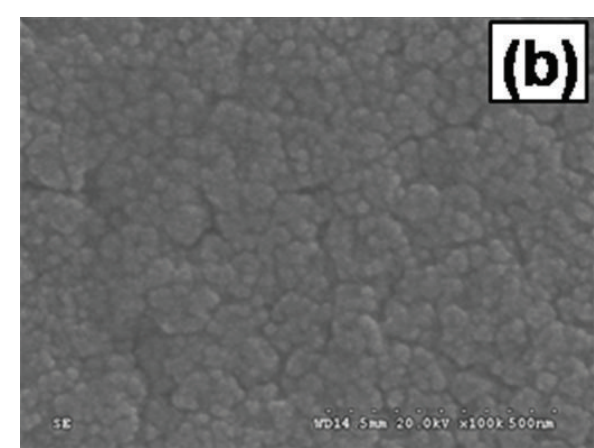

(b)

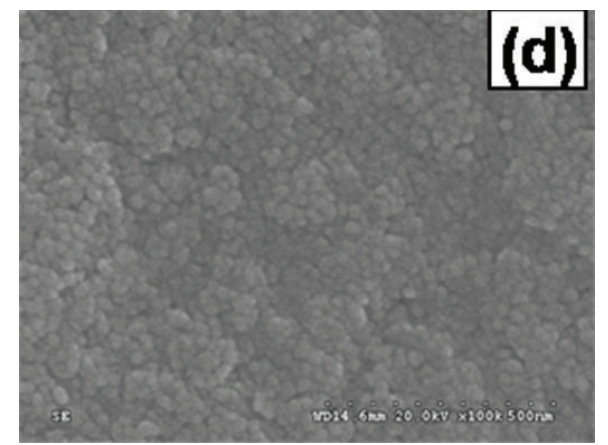

(d)

FIGURE 4: FESEM images showing the surface morphology of the doped $\mathrm{ZnO}$ films with different $\mathrm{Cu}$ doping concentrations. (a) $0.1 \mu \mathrm{M} \mathrm{Cu}{ }^{2+}$, (b) $0.3 \mu \mathrm{M} \mathrm{Cu}^{2+}$, (c) $1.3 \mu \mathrm{M} \mathrm{Cu}^{2+}$, and (d) $26.4 \mu \mathrm{M} \mathrm{Cu}^{2+}$ concentrations. 


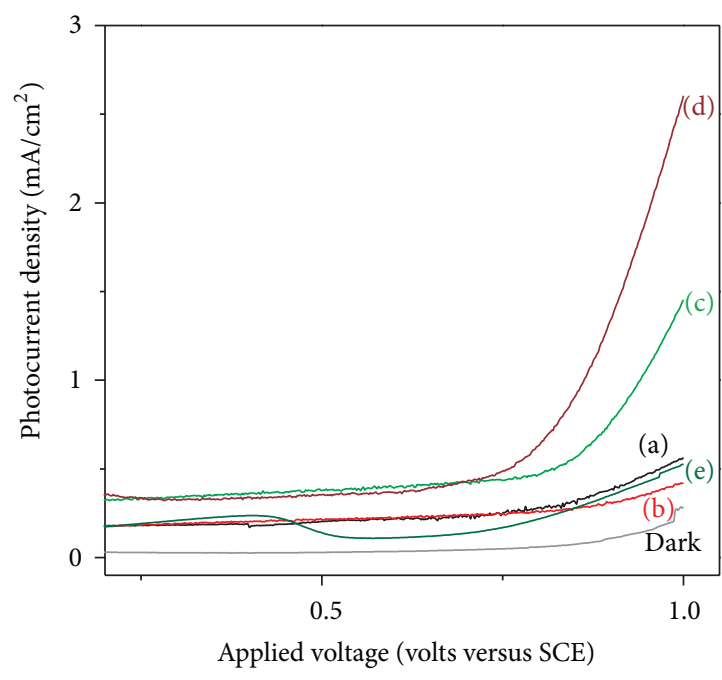
(a) Undoped
(b) $0.1 \mu \mathrm{M} \mathrm{Cu}^{2+}$
(d) $1.3 \mu \mathrm{M} \mathrm{Cu}^{2+}$
(e) $26.4 \mu \mathrm{M} \mathrm{Cu}^{2+}$

(c) $0.3 \mu \mathrm{M} \mathrm{Cu}^{2+}$

(a)

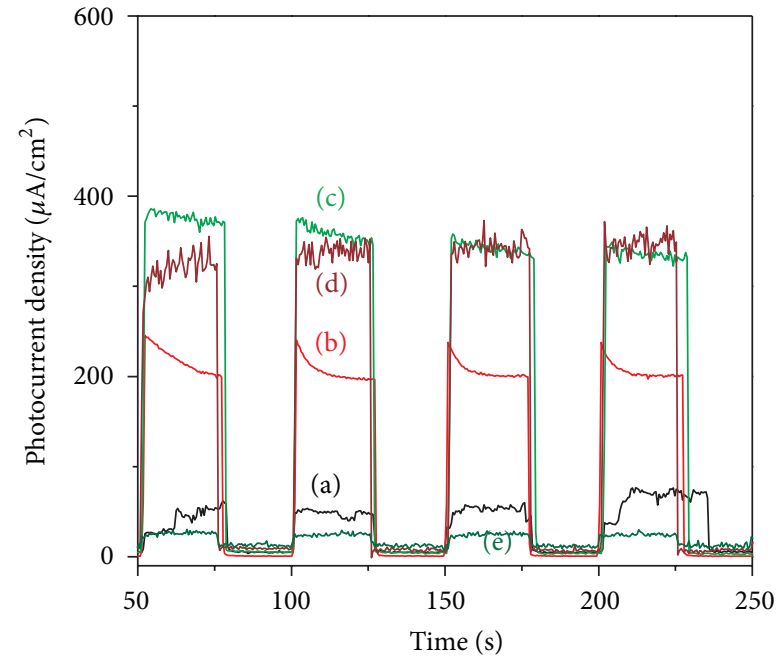
(a) Undoped
(b) $0.1 \mu \mathrm{M} \mathrm{Cu}^{2+}$
(d) $1.3 \mu \mathrm{M} \mathrm{Cu}^{2+}$
(e) $26.4 \mu \mathrm{M} \mathrm{Cu}^{2+}$

(c) $0.3 \mu \mathrm{M} \mathrm{Cu}^{2+}$

(b)

FIGURE 5: (a) Photocurrent potential curves under solar simulator (AM1.5G) for doped ZnO films with different doping concentrations. (b) Photocurrent transients of the same films at an applied bias voltage of $0.6 \mathrm{~V}$ versus SCE under ON/OFF conditions.

Figure 5(b) displays the photocurrent transients of respective photoanodes at an applied voltage of $0.6 \mathrm{~V}$. It clearly shows that the photoanodes with the doping concentrations $0.3 \mu \mathrm{M}$ and $1.3 \mu \mathrm{M}$ generate nearly the same photocurrent under $0.6 \mathrm{~V}$ bias. Both films show a rather stable performance as compared to the other films. This confirms that the doping not only yields a high photocurrent but also yields a rather stable photocurrent generation. This result and the conclusions drawn from structural and optical characterizations indicate that doped film is well suited for solar hydrogen generation as well as for electric power generation. It is worth stating here that our initial hydrogen evolution measurements to estimate evolved hydrogen clearly demonstrate that under simulated solar radiation the rate of hydrogen evolution increased from $18 \mu \mathrm{M} / \mathrm{h}$ (for $\mathrm{ZnO}$ ) to $377 \mu \mathrm{M} / \mathrm{h}$ (for $0.3 \mu \mathrm{M} \mathrm{Cu}^{+2}$ ).

Figure 6 displays the Solar-to-Hydrogen conversion efficiency of undoped and $\mathrm{Cu}$-doped $\mathrm{ZnO}$ photoanodes (concentration range 0 to $26.4 \mu \mathrm{M}$ ). The conversion efficiencies are estimated using the following equation [43]:

$$
\mathrm{STH} \%=\frac{\left(1.23-V_{b}\right) * I_{\mathrm{ph}}}{P_{\text {in }}},
$$

where $I_{\text {ph }}$ is the photocurrent density, $P$ is the input power irradiance of the light source, and $V_{b}$ is the bias voltage (here $0.6 \mathrm{~V}$ versus SCE). A maximum of $0.28 \% \mathrm{STH}$ conversion efficiency was displayed by photoanodes with the dopant concentration being equal to $1.3 \mu \mathrm{M}$. As the order of "initial $\mathrm{Cu}$ doping concentration" was varied, the STH was found to vary as shown in the figure. The study clearly demonstrates that at an optimum $\mathrm{Cu}$-doping $(1.3 \mu \mathrm{M})$ concentration, the photoanode shows improved and efficient STH performance. This is

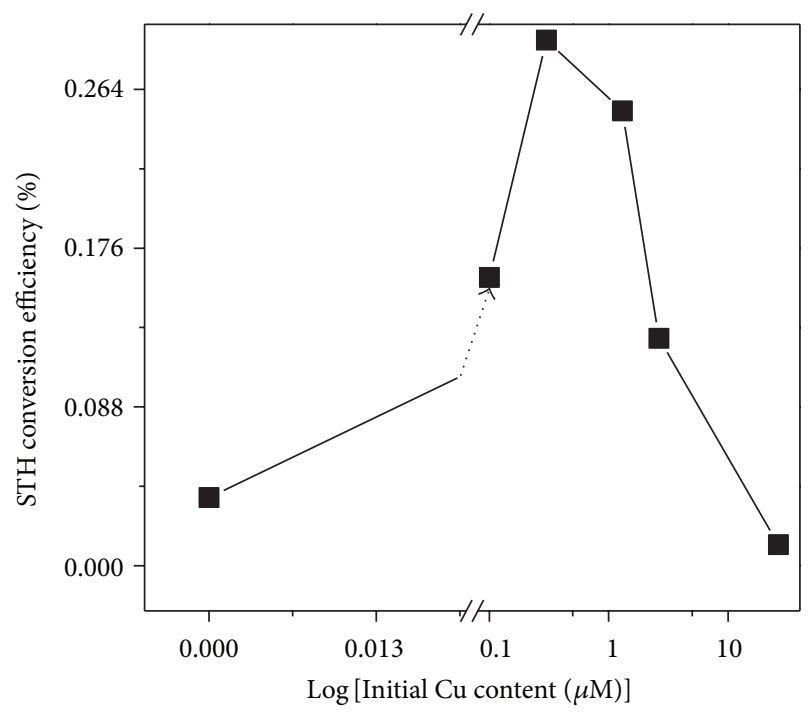

FIGURE 6: STH conversion efficiency of the doped $\mathrm{ZnO}$ films with different doping concentrations in the range $0-26.4 \mu \mathrm{M}$.

also in line with the observations from the other characterizations. This clearly indicates that a photoanode with best absorption properties, low defect density, and high photocurrent is achieved. It is necessary to recall that this optimum $\mathrm{Cu}$-doped concentration photoanode yielded the highest hydrogen during PEC water-splitting experiments.

Further, we investigated the wavelength-dependent conversion efficiency of these photoanodes. The incidentphoton-current conversion efficiency (IPCE) is estimated 


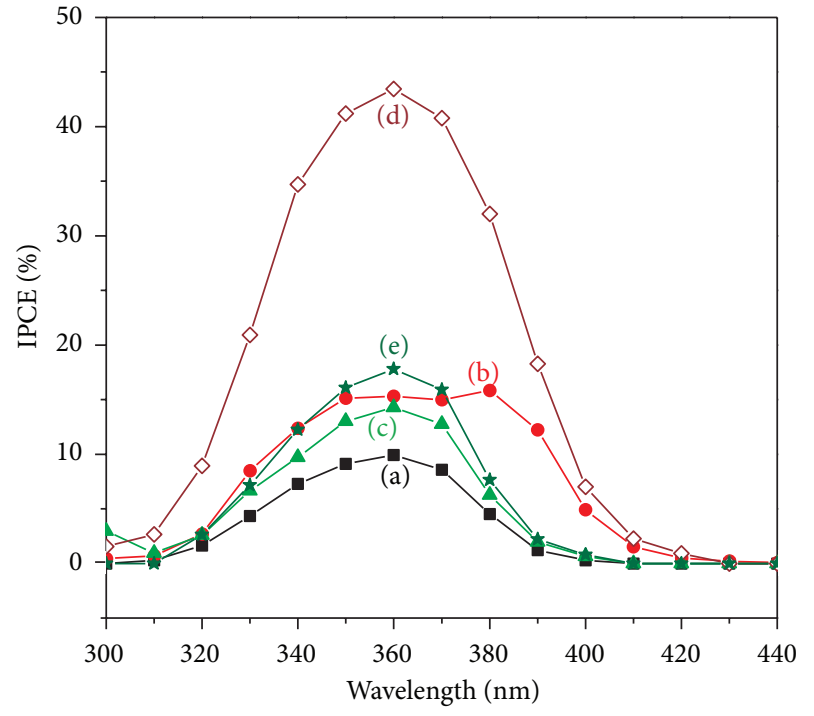
(a) Undoped
(b) $0.1 \mu \mathrm{M} \mathrm{Cu}^{2+}$
(c) $0.3 \mu \mathrm{M} \mathrm{Cu}^{2+}$
(d) $1.3 \mu \mathrm{M} \mathrm{Cu}^{2+}$
(e) $26.4 \mu \mathrm{M} \mathrm{Cu}^{2+}$

FIGURE 7: IPCE conversion efficiency for the $\mathrm{ZnO}$ films of different doping concentrations.

from the generated photocurrents using the following formula [6]:

$$
\mathrm{IPCE} \%=\frac{1240 * I_{\mathrm{ph}}}{\lambda * J_{s s}},
$$

where $I_{\mathrm{ph}}$ is the photocurrent density $\left(\mathrm{mA} / \mathrm{cm}^{2}\right), \lambda$ the incident wavelength $(\mathrm{nm})$, and $J_{s s}$ is the incident irradiance ( $\mathrm{mW} /$ $\mathrm{cm}^{2}$ ).

Wavelength dependence of IPCE displayed in Figure 7 clearly shows that in contrast to undoped film, optimum $\mathrm{Cu}$ doped film shows IPCE curve, which extends to the larger wavelengths encompassing the visible light part of the electromagnetic radiation. As undoped $\mathrm{ZnO}$ exhibits large band gap $(3.2 \mathrm{eV})$, thus expectedly it is active in the ultra-violet part of electromagnetic radiation. Overall, the IPCE performance of all the films showed superior performance as seen from the IPCE intensity. The photoanode with the $1.3 \mu \mathrm{M} \mathrm{Cu}$ exhibited IPCE of $43 \%$ at $360 \mathrm{~nm}$ wavelength. The study confirms that the $\mathrm{Cu}$ doping has tuned the optical absorption properties of the films, which resulted in the red shift of the IPCE onset in a similar as shown in the optical absorption studies. The results show a direct implication of doping on improvement of the PEC performance of photoanode.

Electrochemical impedance spectroscopy measurements were carried out on pure and doped $\mathrm{ZnO}$ photoanodes under dark conditions. Mott-Schottky (M-S) plot [44] of Figure 8 shows the variation in the functional of capacitances at the semiconductor-electrolyte interface as deduced from respective equivalent circuit. The flat-band potential of the undoped and doped photoanodes is estimated from M-S plots and the results are tabulated in Table 2. Additionally, the results from optical and PEC measurements are shown for the sake

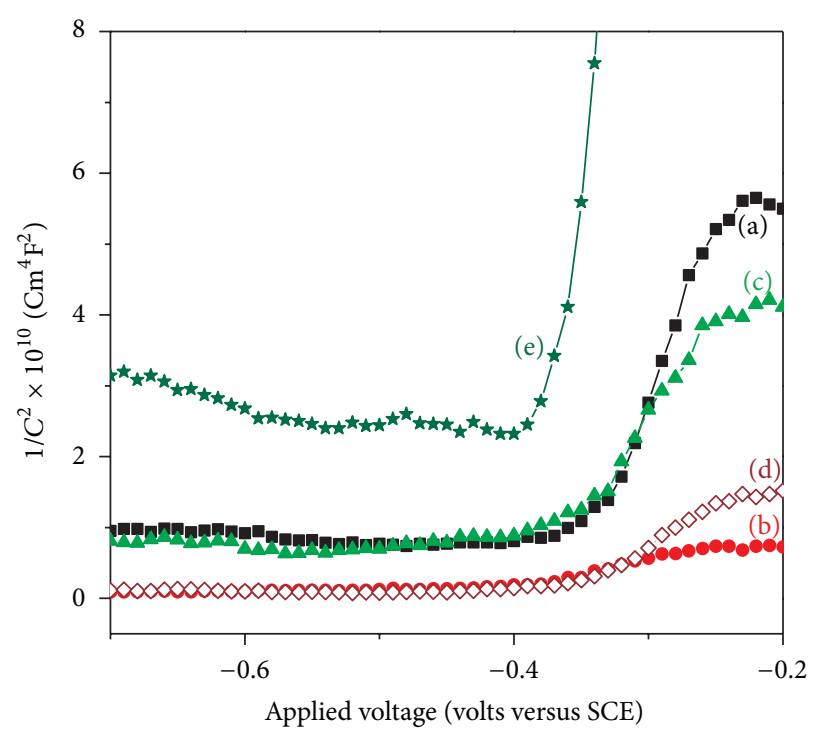
(a) Undoped
(b) $0.1 \mu \mathrm{M} \mathrm{Cu}{ }^{2+}$
(c) $0.3 \mu \mathrm{M} \mathrm{Cu}^{2+}$
(d) $1.3 \mu \mathrm{M} \mathrm{Cu}^{2+}$
(e) $26.4 \mu \mathrm{M} \mathrm{Cu}^{2+}$

Figure 8: Mott-Schottky plots of the undoped and doped $\mathrm{ZnO}$ films.

of completeness. These plots clearly reveal the n-type nature of the films. This observation is similar to the report in the literature [39] which shows that low $\mathrm{Cu}$-doping concentration in $\mathrm{ZnO}$ films yields an $n$-type film. The results shown in Table 2 thus demonstrate that as the initial $\mathrm{Cu}$-doping concentration increases, there is a reduction in the band-gap for $\mathrm{Cu}$-doping concentrations of 1.3 and $26.4 \mu \mathrm{M}$. On the other hand, the photocurrents show an increasing trend up to $1.3 \mu \mathrm{M}$ film, but further they show a decrease in photocurrent beyond this point.

In brief, the study reveals that the doping of $\mathrm{Cu}$ into the $\mathrm{ZnO}$ lattice at a very low concentration did not alter the host lattice structure as confirmed from the XRD studies. On the contrary, an increase in the $\mathrm{Cu}$-doping concentration yielded a red-shifted band gap expectedly due to the incorporation of $\mathrm{Cu}$ into the $\mathrm{ZnO}$ lattice. Doping yielded enhanced photocurrents of around 7 times, thus yielding an efficient hydrogenproducing film. The red shift in the band gap as well as the IPCE onset with the increase in $\mathrm{Cu}$ content indicates that these photoanodes are efficient solar absorbers and thus may be feasible for several other solar conversion applications.

\section{Conclusions}

Simple spray pyrolysis deposition technique was adopted to obtain $\mathrm{ZnO}$ films with $\mathrm{Cu}$ doping. The influence of doping concentration on different properties was investigated. XRD analysis verified the wurtzite structure of $\mathrm{ZnO}$ films without any secondary phase formation or strain produced by $\mathrm{Cu}$ doping. The optical studies revealed a red shift in the band gap of the $\mathrm{Cu}$-doped films with high concentration of doping which was well in accordance with the IPCE measurements. Film deposited using initial $\mathrm{Cu}^{2+}$ concentration of $1.3 \mu \mathrm{M}$ 
concentration yielded high photocurrents under solar simulator. The film displayed an enhancement of nearly 7 times as compared to the undoped film under $0.6 \mathrm{~V}$ bias condition. STH conversion efficiencies estimated for the films with doping concentration in the range $10^{-4}-10^{-1}$ indicated higher efficiencies for the films with $10^{-3} \%$ doping which is again 7 times than the undoped film. This is the highest enhancement in the conversion efficiency under solar light reported so far which indicates high potential of the deposited $\mathrm{ZnO}$ films for solar energy applications.

\section{Acknowledgments}

The authors thank the Director, ARCI, for granting permission to publish the work. Rekha Dom also acknowledges the support extended by Professor A. Sadananda Chary, Department of Physics, Osmania University, India, towards doctoral studies.

\section{References}

[1] A. Fujishima and K. Honda, "Electrochemical photolysis of water at a semiconductor electrode," Nature, vol. 238, no. 5358, pp. 37-38, 1972.

[2] S. U. M. Khan, M. Al-Shahry, and W. B. Ingler Jr., "Efficient photochemical water splitting by a chemically modified n- $\mathrm{TiO}_{2}$," Science, vol. 297, no. 5590, pp. 2243-2245, 2002.

[3] N. S. Lewis, "Toward cost-effective solar energy use," Science, vol. 315, no. 5813, pp. 798-801, 2007.

[4] O. Khaselev and J. A. Turner, "A monolithic photovoltaicphotoelectrochemical device for hydrogen production via water splitting," Science, vol. 280, no. 5362, pp. 425-427, 1998.

[5] Y. K. Hsu, Y. C. Chen, Y. G. Lin, L. C. Chen, and K. H. Chen, "Birnessite-type manganese oxides nanosheets with hole acceptor assisted photoelectrochemical activity in response to visible light," Journal of Materials Chemistry, vol. 22, no. 6, pp. 27332739, 2012.

[6] A. Wolcott, W. A. Smith, T. R. Kuykendall, Y. Zhao, and J. Z. Zhang, "Photoelectrochemical study of nanostructured $\mathrm{ZnO}$ thin films for hydrogen generation from water splitting," Advanced Functional Materials, vol. 19, no. 12, pp. 1849-1856, 2009.

[7] M. Grätzel, "Photoelectrochemical cells," Nature, vol. 414, no. 6861, pp. 338-344, 2001.

[8] T. Bak, J. Nowotny, M. Rekas, and C. C. Sorrell, "Photo-electrochemical hydrogen generation from water using solar energy. Materials-related aspects," International Journal of Hydrogen Energy, vol. 27, no. 10, pp. 991-1022, 2002.

[9] R. Asahi, T. Morikawa, T. Ohwaki, K. Aoki, and Y. Taga, "Visible-light photocatalysis in nitrogen-doped titanium oxides," Science, vol. 293, no. 5528, pp. 269-271, 2001.

[10] M. Shi, X. Pan, W. Qiu, D. Zheng, M. Xu, and H. Chen, "Si/ZnO core-shell nanowire arrays for photoelectrochemical water splitting," International Journal of Hydrogen Energy, vol. 36, no. 23, pp. 15153-15159, 2011.

[11] A. M. Basilio, Y. Hsu, W. Tu et al., "Enhancement of the energy photoconversion efficiency through crystallographic etching of a c-plane GaN thin film," Journal of Materials Chemistry, vol. 20, no. 37, pp. 8118-8125, 2010.

[12] X. H. Zhao, P. Wang, and B. J. Li, "CuO/ZnO core/shell heterostructure nanowire arrays: synthesis, optical property, and energy application," Chemical Communications, vol. 46, no. 36, pp. 6768-6770, 2010.

[13] J. Shi, Y. Hara, C. L. Sun, M. A. Anderson, and X. Wang, "Threedimensional high-density hierarchical nanowire architecture for high-performance photoelectrochemical electrodes," Nano Letters, vol. 11, no. 8, pp. 3413-3419, 2011.

[14] M. Tonezzer and R. G. Lacerda, "Integrated zinc oxide nanowires/carbon microfiber gas sensors," Sensors and Actuators B, vol. 150, no. 2, pp. 517-522, 2010.

[15] U. Özgür, Y. I. Alivov, C. Liu et al., "A comprehensive review of $\mathrm{ZnO}$ materials and devices," Journal of Applied Physics, vol. 98, no. 4, Article ID 041301, pp. 1-103, 2005.

[16] X. Yang, A. Wolcott, G. Wang et al., "Nitrogen-doped ZnO nanowire arrays for photoelectrochemical water splitting," Nano Letters, vol. 9, no. 6, pp. 2331-2336, 2009.

[17] J. Wang, V. Sallet, F. Jomard et al., "Influence of substrate temperature on $\mathrm{N}$-doped $\mathrm{ZnO}$ films deposited by $\mathrm{RF}$ magnetron sputtering," Thin Solid Films, vol. 515, no. 24, pp. 8785-8788, 2007.

[18] M. Jakani, G. Campet, J. Claverie, D. Fichou, J. Pouliquen, and J. Kossanyi, "Photoelectrochemical properties of zinc oxide doped with 3d elements," Journal of Solid State Chemistry, vol. 56, no. 3, pp. 269-277, 1985.

[19] E. M. Kaidashev, M. Lorenz, H. Von Wenckstern et al., "High electron mobility of epitaxial $\mathrm{ZnO}$ thin films on c-plane sapphire grown by multistep pulsed-laser deposition," Applied Physics Letters, vol. 82, no. 22, pp. 3901-3903, 2003.

[20] V. Dhas, S. Muduli, W. Lee, S. Han, and S. Ogale, "Enhanced conversion efficiency in dye-sensitized solar cells based on $\mathrm{ZnO}$ bifunctional nanoflowers loaded with gold nanoparticles," Applied Physics Letters, vol. 93, no. 24, pp. 3108-3110, 2008.

[21] A. A. Tahir and K. G. U. Wijayantha, "Photoelectrochemical water splitting at nanostructured $\mathrm{ZnFe}_{2} \mathrm{O}_{4}$ electrodes," Journal of Photochemistry and Photobiology A, vol. 216, no. 2-4, pp. 119125, 2010.

[22] V. Sharma, P. Kumar, J. Shrivastava et al., "Synthesis and characterization of nanocrystalline $\mathrm{Zn}_{1-x} \mathrm{M}_{x} \mathrm{O}(\mathrm{M}=\mathrm{Ni}, \mathrm{Cr})$ thin films for efficient photoelectrochemical splitting of water under UV irradiation," International Journal of Hydrogen Energy, vol. 36, no. 7, pp. 4280-4290, 2011.

[23] V. Sharma, P. Kumar, N. Singh et al., "Photoelectrochemical water splitting with nanocrystalline $\mathrm{Zn}_{1-x} \mathrm{Ru}_{x} \mathrm{O}$ thin films," International Journal of Hydrogen Energy, vol. 37, no. 17, pp. 12138-12149, 2012.

[24] S. Dong, K. Xu, J. Liu, and H. Cui, "Photocatalytic performance of $\mathrm{ZnO}$ :Fe array films under sunlight irradiation," Physica B, vol. 406, no. 19, pp. 3609-3612, 2011.

[25] Y. Zhang, M. K. Ram, E. K. Stefanakos, and D. Y. Goswami, "Enhanced photocatalytic activity of iron doped zinc oxide nanowires for water decontamination," Surface and Coatings Technology, vol. 217, pp. 119-125, 2013.

[26] C. Wu, L. Shen, Y. Zhang, and Q. Huang, "Solvothermal synthesis of $\mathrm{Cr}$-doped $\mathrm{ZnO}$ nanowires with visible light-driven photocatalytic activity," Materials Letters, vol. 65, no. 12, pp. 1794-1796, 2011.

[27] Y. Lu, Y. Lin, D. Wang, L. Wang, T. Xie, and T. Jiang, "A high performance cobalt-doped $\mathrm{ZnO}$ visible light photocatalyst and its photogenerated charge transfer properties," Nano Research, vol. 4, no. 11, pp. 1144-1152, 2011.

[28] L. Bahadur and T. N. Rao, "Photoelectrochemical studies of cobalt-doped $\mathrm{ZnO}$ sprayed thin film semiconductor electrodes 
in acetonitrile medium," Solar Energy Materials and Solar Cells, vol. 27, no. 4, pp. 347-360, 1992.

[29] T. Jia, W. Wang, F. Long, Z. Fu, H. Wang, and Q. Zhang, "Fabrication, characterization and photocatalytic activity of Ladoped $\mathrm{ZnO}$ nanowires," Journal of Alloys and Compounds, vol. 484, no. 1-2, pp. 410-415, 2009.

[30] J. Ishihara, A. Nakamura, S. Shigemori, T. Aoki, and J. Temmyo, " $\mathrm{Zn}_{1-x} \mathrm{Cd}_{x} \mathrm{O}$ systems with visible band gaps," Applied Physics Letters, vol. 89, no. 9, Article ID 091914, pp. 1914-1917, 2006.

[31] Y. Li, X. Zhao, and W. Fan, "Structural, electronic, and optical properties of Ag-doped $\mathrm{ZnO}$ nanowires: first principles study," Journal of Physical Chemistry C, vol. 115, no. 9, pp. 3552-3557, 2011.

[32] J. Min, X. Liang, B. Wang, Y. Zhao, Y. Guo, and L. Wang, "Characterization of Ag doped P-type $\mathrm{ZnO}$ thin films prepared by electrostatic-enhanced ultrasonic spray pyrolysis," Advanced Materials Research, vol. 299-300, pp. 436-439, 2011.

[33] M. Öztas and M. Bedir, "Thickness dependence of structural, electrical and optical properties of sprayed $\mathrm{ZnO}: \mathrm{Cu}$ films," Thin Solid Films, vol. 516, no. 8, pp. 1703-1709, 2008.

[34] M. B. Rahmani, S. H. Keshmiri, M. Shafiei et al., “Transition from $n$ - to $P$-type of spray pyrolysis deposited $\mathrm{Cu}$ doped $\mathrm{ZnO}$ thin films for $\mathrm{NO}_{2}$ sensing," Sensor Letters, vol. 7, no. 4, pp. 621628, 2009.

[35] B. Mari, M. Sahal, M. A. Mollar, F. M. Cerqueira, and A. P. Samantineke, "P-type behavior of electrodeposited $\mathrm{ZnO}: \mathrm{Cu}$ films," Journal of Solid State Electrochemistry, vol. 16, no. 6, pp. 2261-2265, 2012.

[36] P. Jongnavakit, P. Amornpitoksuk, S. Suwanboon, and N. Ndiege, "Preparation and photocatalytic activity of $\mathrm{Cu}$-doped $\mathrm{ZnO}$ thin films prepared by the sol-gel method," Applied Surface Science, vol. 258, no. 20, pp. 8192-8198, 2012.

[37] R. Mohan, K. Krishnamoorthy, and S. Kim, "Enhanced photocatalytic activity of $\mathrm{Cu}$-doped $\mathrm{ZnO}$ nanorods," Solid State Communications, vol. 152, no. 5, pp. 375-380, 2012.

[38] V. Sharma, P. Kumar, J. Shrivastava et al., "Vertically aligned nanocrystalline $\mathrm{Cu}-\mathrm{ZnO}$ thin films for photoelectrochemical splitting of water," Journal of Materials Science, vol. 46, no. 11, pp. 3792-3801, 2011.

[39] Y. K. Hsu and C. M. Lin, "Enhanced photoelectrochemical properties of ternary $\mathrm{Zn}_{1-x} \mathrm{Cu}_{x} \mathrm{O}$ nanorods with tunable band gaps for solar water splitting," Electrochemica Acta, vol. 74, pp. 73-77, 2012.

[40] B. D. Cullity, Elements of X-Ray Diffraction, Addison-Wesley, Reading, Mass, USA, 2nd edition.

[41] E. Zolotoyabko, J. L. M. Rupp, and L. J. Gauckler, "Interrelationship between grain size-induced and strain-induced broadening of X-ray diffraction profiles: what we can learn about nanostructured materials?" Scripta Materialia, vol. 66, no. 3-4, pp. 190-193, 2012.

[42] J. Tauc, R. Grivorovici, and A. Vancu, "Optical properties and electronic structure of amorphous germanium," physica Status Solidi B, vol. 15, no. 2, pp. 627-637, 1966.

[43] M. G. Walter, E. L. Warren, J. R. McKone et al., "Solar water splitting cells," Chemical Reviews, vol. 110, no. 11, pp. 6446-6473, 2010.

[44] A. J. Bard and L. R. Faulkener, Electrochemical Methods-Fundamentals and Applications, John Wiley \& Sons, New York, NY, USA, 2nd edition, 2001. 

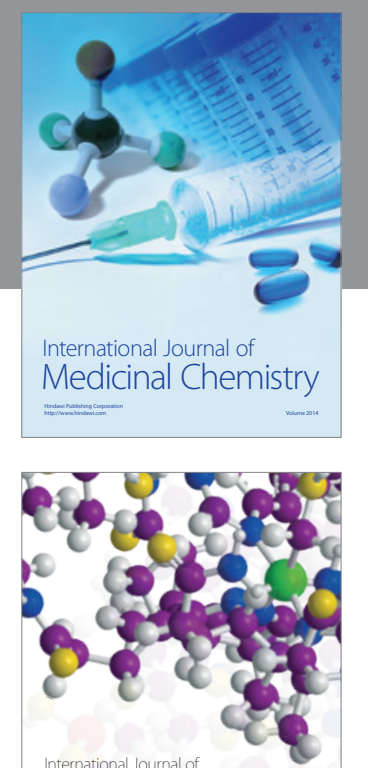

\section{Carbohydrate} Chemistry

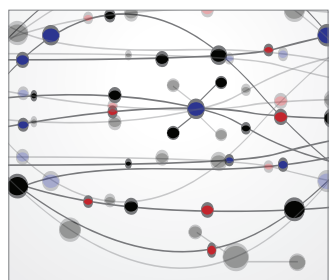

The Scientific World Journal
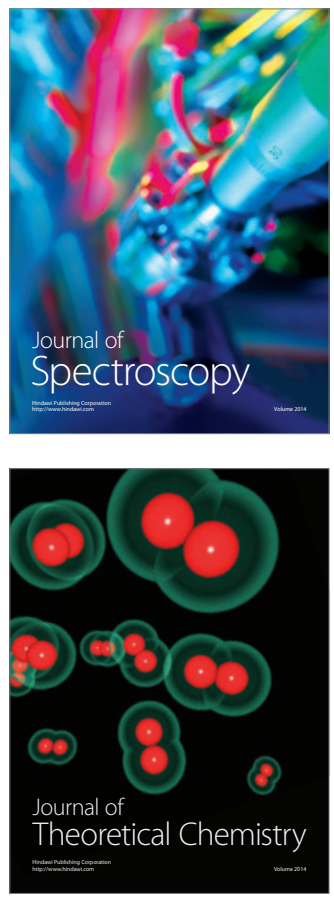
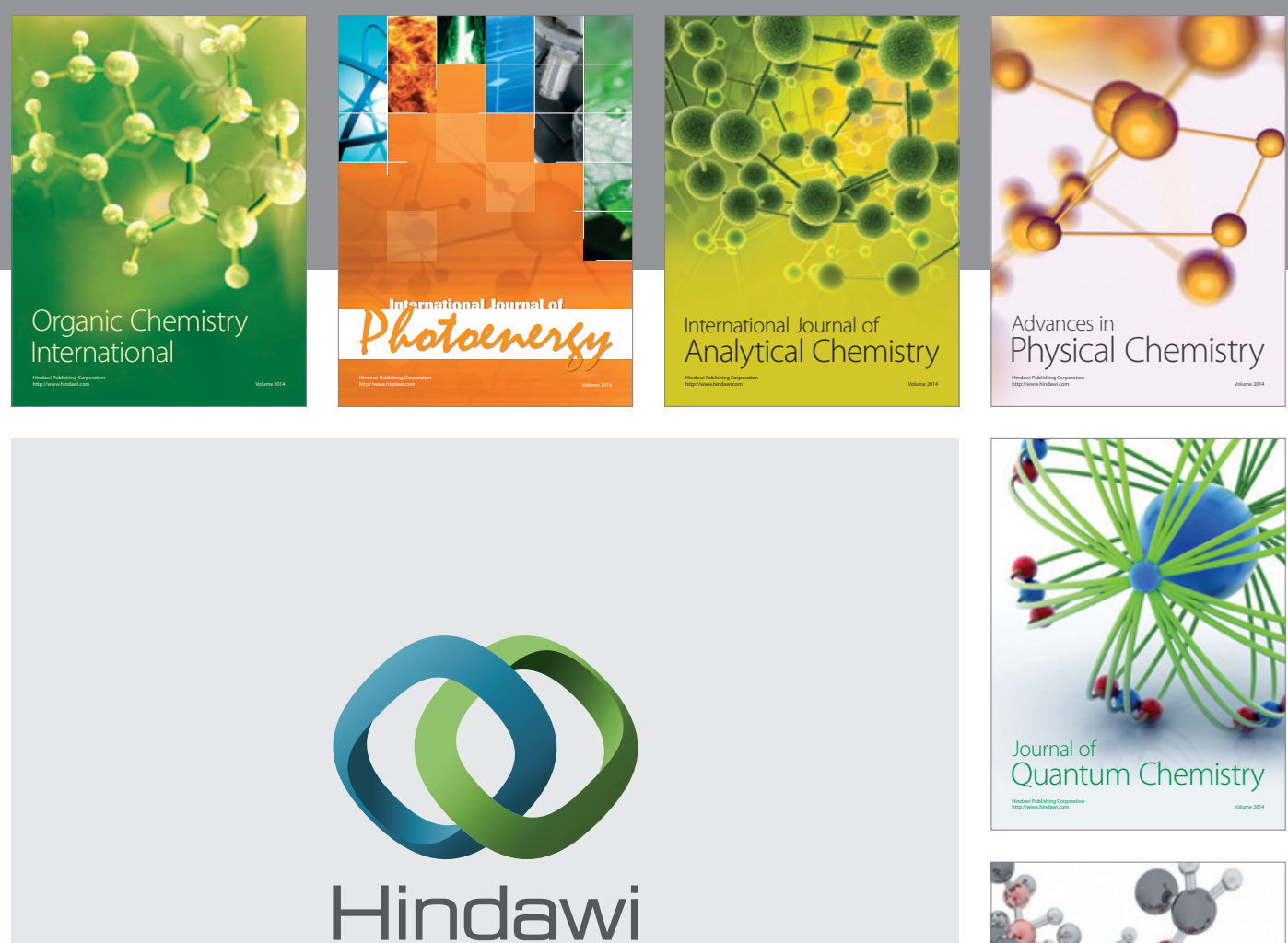

Submit your manuscripts at

http://www.hindawi.com

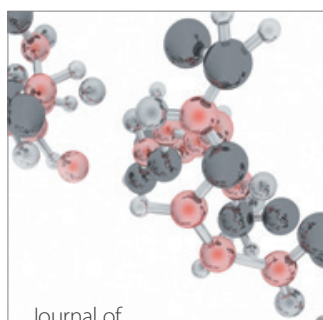

Analytical Methods

in Chemistry

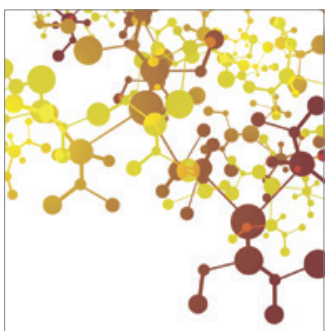

Journal of

Applied Chemistry

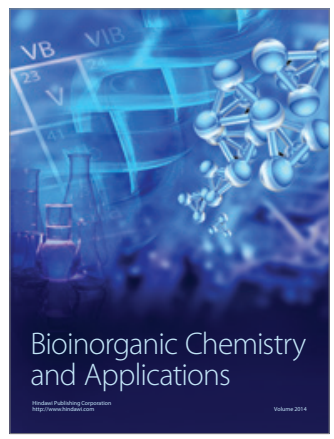

Inorganic Chemistry
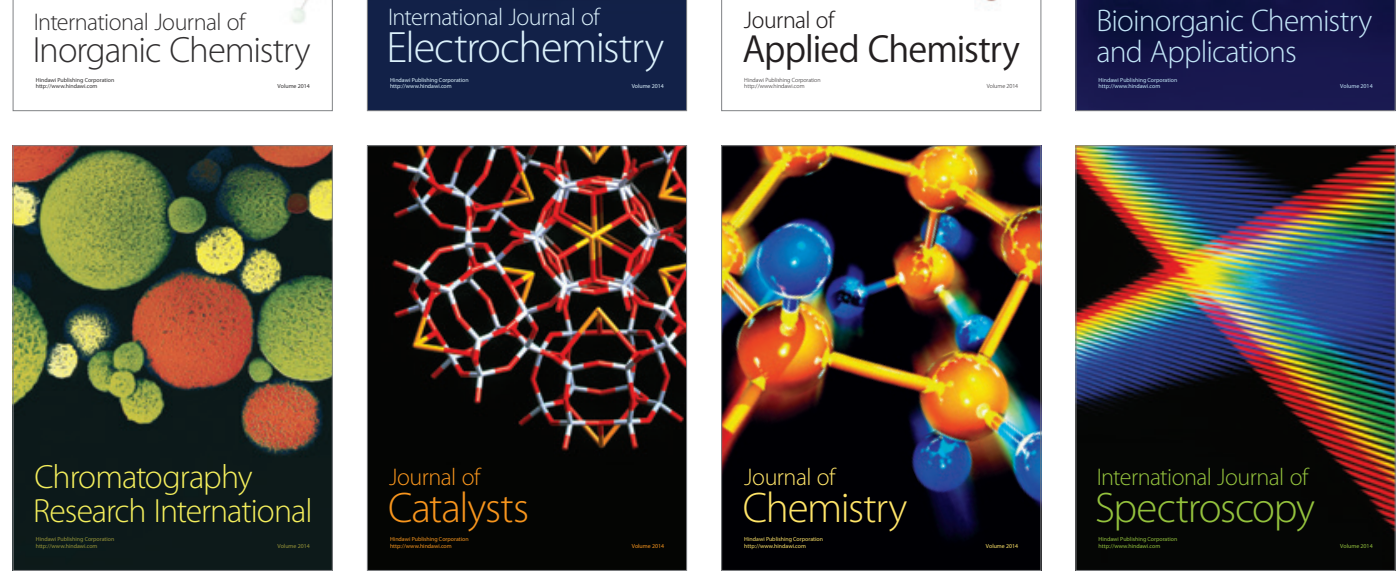